\title{
Lifestyle and dietary pattern of diabetic patients
}

\author{
Soni Kumari and Seema Dey
}

Received: 23.01.2020; Revised: 11.03.2020; Accepted: 25.04.2020

See end of the paper for authors' affiliations

\section{Seema Dey}

University Department of Home Science, Ranchi University,

Ranchi (Jharkhand) India

Email : seemadey@ rediffmail.

com
ABSTRACT : Diabetes mellitus is a chronic metabolic disorder that prevents the body to utilize glucose completely or partially. It is characterized by raised glucose concentration in the blood and alterations in carbohydrate, protein and fat metabolism. The prevalence of diabetes in India is reaching alarming proportions. The present study was design to access the dietary pattern and life style behaviour of diabetic patients. Total 300 diabetes type -2 patients from five hospitals of Ranchi districts were purposively selected. Maximum 51.33 per cent reported diet control is the prime factor for diabetic patients. Diet is the single most important factor in the successful treatment of diabetes. Inspite of all advance medical treatment diet has maintained its supremacy. Despite frequent intake of meals continual loss of weight is the symptom of diabetes. Forty-seven per cent families had strong hereditary tendency to diabetes. The family plays an important role both in health and diseases in the prevention and treatment of individual illness. Health care is the primary necessity of the society.

KEY WORDS: Diet, Lifestyle, Consumption pattern

- HOW TO CITE THIS PAPER : Kumari, Soni and Dey, Seema (2020). Lifestyle and dietary pattern of diabetic patients. Asian J. Home Sci., 15 (1) : 54-57, DOI: 10.15740/HAS/AJHS/15.1/54-57. Copyright@ 2020: Hind Agri-Horticultural Society. 